Research Article

\title{
Novel insights on greek students' coping strategies
}

\begin{abstract}
College life requires more physical and emotional resources from students than high school. As a result of these higher demands, it is common for college students to experience greater levels of stress. If stress is not dealt with effectively, individuals suffer psychological symptoms such as low self esteem, reduced motivation, anxiety, depression. Effective coping strategies facilitate the return to a balanced state, reducing the negative effects of stress.

The data collection was carried out by filling anonymously the Toulouse's scale of Coping, which consists of 54 statements expressing coping strategies. In total, 18 positive and negative coping strategies, classified in six strategy categories (focus, social support, withdrawal, change of attitude, control, denial) and three strategy fields (behavioural, information seeking, emotional) were tested. The use of the studied strategies was quantified in three levels (low, moderate, high). The study cohort $(\mathrm{n}=999)$ was recruited from the Greek educational system, among 5 cities of Greece. The data show that all coping strategies are used by the majority of the study participants $(>95 \%)$, though the intensity may vary from person to person, leading to different mean values. Women, as expected were found to implement more coping strategies in general, with social support, change and withdrawal to be applied the most $(\mathrm{p}<0,0001)$. No statistically significant differences were found concerning age or place of origin, as expected. Surprisingly, even though all students employ a variety of coping strategies, geographical location of each college or university may favor a preference towards certain strategies. Consequently, there is evidence that physical surroundings and learning environment of smaller university cities influence coping strategies, such as social support, emotion, positive strategies and focus.
\end{abstract}

Keywords: greek students, stress management, coping strategies, place of study, enviroment's influence, social support

Volume 8 Issue I - 2017

\author{
Theodoratou M,' Kalpini Papadopoulou \\ $\mathrm{CH},{ }^{\prime}$ Kiritsi V,' Evagelatou M,' Athanassia \\ Plitsi,' Pistola D,' Andreopoulou $\mathrm{O}^{2}$ \\ 'T.E.I. of Western Greece, School of Health and Welfare \\ Professions, Greece \\ ${ }^{2}$ Deaprtment of Psychiatry, University of Patras, Greece
}

Correspondence: Maria Theodoratou, Clinical Psychologist, Technological Institute of Patras, School of Health and Welfare Professions, Patras, Greece, Email mttheoria@gmail.com

Received: July 26, 2017| Published: August 30, 2017

\section{Background}

Academic stress among college students has been a topic of interest for many years. College students, especially freshmen, are particularly prone to stress due to the transitional nature of college life. Moreover, a student's life is subjected to different kinds of stressors, such as the pressure of academics with an obligation of success, uncertain future and difficulties envisaged for integration into the system. Some of them find it hard to cope with the stress and lag behind, while others see the pressure as challenge to work harder. ${ }^{1}$ Studies showed that almost $90 \%$ of the students have experienced severe stress at one time or another, during their studies. ${ }^{2}$ The transition from high school to university is a major life change for many adolescents and can be a source of strain and an acute stressor. ${ }^{3}$ Specifically, stress may result from being separated from home for the first time, the transition from a personal to an impersonal academic environment, or the very structure of the academic experience at the college level. Students may have difficulty adjusting to more rigorous academic expectations and the need to learn to deal with individuals of differing cultures and beliefs. ${ }^{4}$ The young person has to adjust from the strictly structured educational system of senior high Institution to the University's system, which is characterized by a wide variety of choices. At the same time, the young person moves from a usually overprotective familial environment to a more demanding milieu. ${ }^{5}$ Academic demands increase and new social relations are established. ${ }^{6}$ Also the importance of performing adequately on tests without second chances or alternative ways of raising one's grade proved to cause great stress. ${ }^{4}$ All these stressors can be understood within the framework of the cognitive-relational theory that emphasizes the relationship between the affected person's appraisal of environmental demands and personal resources. ${ }^{7}$ In terms of coping strategies, the theory identifies two major functions: problem focused scoping and emotion focused coping. The first category actively engages the stressor to overcome it. ${ }^{7}$ This is considered to be more adaptive particularly in situations, where the stressor is changeable. Emotion focused strategies on the other hand, are efforts directed to minimize the negative effects of the stressor. ${ }^{8}$ They insulate the individual by focusing on changing thoughts and feelings about one's situation. Emotion focused strategies are used where the stressor is perceived as extremely threatening and uncontrollable. Generally, the two categories of strategies are used in combinations. ${ }^{9}$ Various studies report different kind of coping strategies used by students to alleviate stress. For example, some students use alcohol,${ }^{10}$ while others have reported the use of other substances, such as tobacco and drugs ${ }^{11},{ }^{12}$ or sports. ${ }^{2}$ Research report that the use of problem -focused strategies was associated with positive outcomes, such as better health and reduced negative affect, ${ }^{13}$ while college students' use of emotional -focused strategies was associated with negative outcomes, such as poorer health and increased negative affect. ${ }^{14}$ Bibliography on the role of the sex on the use of coping strategies report that male appear to use more direct and active coping strategies, while women engaged in more passive coping strategies such as religion, social support and distraction. These differences are consistent with the socialization theory which suggests that men and women approach stressors according to their differential social role that men and women occupy. ${ }^{15}$

Felsten \& Wilcox ${ }^{16}$ found that higher levels of stress reduced grade point averages and led to increased psychological and somatic symptomatology. ${ }^{17}$ It seems that stress can lead to disruptions in both physical \& mental health. ${ }^{17}$ Stress reduction and adopting a healthier life style has been a major concern for students. ${ }^{18}$ Because the way in which an individual copes with stress relates to mental and physical 
well being, ${ }^{19}$ the ability to successfully cope in University is crucial for success. Coping style do not remain static but change throughout the lifetime and the university experience may prove an avenue for change. ${ }^{14}$ To our knowledge very few studies so far attempted to investigate the coping strategies adopted by greek students, in order to alleviate academic stress.

\section{Methodology}

Design of the study: The purpose of our study is to investigate the coping strategies used by students facing academic stress, during their studies. The participants were randomly selected independently from origin, family, socio-economic status, studying in Universities of five major cities of Greece. Nine hundred ninety students participated in the study,out of which 393 of the participants were men $(39,7 \%)$ and 597 were women $(60,3 \%)$. The age range students were between $17-25$ and the average age was 20.27years old. For the best possible analysis of the research data, the participants were divided between those coming from southern Greece $(\mathrm{n}=554)$ and those from northern Greece $(n=436)$. The participants were enrolled in Universities (297 participants, 30, 0\%), Technological Educational Institutes (442 participants, 44,6\%) and Professional Learning Institutes (251 participants, $25,4 \%$ ). The study was undertaken with the understanding and written consent of each subject and in full accordance with the principles of the World Medical Association Declaration of Helsinki.

\section{Measures}

The used questionnaire consisted of two parts : The first part contained demographic questions and the second part contained 54 questions of the Toulouse scale for coping strategies, created by
Esparbes et al. ${ }^{20}$ The data was collected by interview and the average time required for each questionnaire was completed in 20 minutes.

\section{Use and description of toulouse's scale for coping strategies}

In the present research we used the Echelle Toulousaine de Coping (ETC) Instrument, formulated by Esparbes et al., ${ }^{21}$ this scale was modified and translated in Greek by Theodoratou M. ${ }^{22}$ The main reason that this particular scale was selected was because of its psychodynamic approach..$^{20}$ This scale has also been tested successfully in three different research groups in the Greek population. ${ }^{23,24}$ The scale's reliability has been established through estimating the internal consistency of the general scale (Cronbach's alpha $>0.80$ ). Coping strategies cover three sections:

a. Behavioural, which represents the processes through which an individual activates oneself, that is to say preparation for action, action and consequences,

b. Information Seeking, which is a cognitive section that determines the procedures with which individuals acquire information from their environment and process this information in order to modulate their behaviour and

c. Emotional, which is the total of non-cognitive and non-active processes, which include simple emotions as well as more complex emotional reactions (Figure 1). The coordination of the above sections allows the emergence of six coping strategies: Focus, Social Support, Withdrawal, Change of Attitude, Control and Denial. Each main strategy is composed of three coping strategies correlated to the three above mentioned sections. The six coping strategy categories are described below:

\begin{tabular}{llll}
\hline Aspects Strategies & Action & Information & Emotion \\
\hline Focus & A.Active focus & G. Cognitive focus & M. Emotional focus \\
Social support & B. Social support & H. Informational Social support & N. EmotionalSocial support \\
Withdrawal & C.Social and behavioral Withdrawal & I. Mental Withdrawal & O.Addiction \\
Change & D.Attitude change & J.Acceptance & P.Values change \\
Control & E.Activities' regulation & K. Cognitive control and planning & Q. Emotional control \\
Denial & F. Entertainment & L. Denial & R.Alexithymia
\end{tabular}

Figure I aspects and dimensions of coping strategies.

1. Focus implies that the individual concentrates on the problem and seeks ways to resolve this problem. This strategy has 3dimensions:

a. A. Active Focus: When one faces the problem directly, takes action or makes efforts to remove or circumvent the stressful condition.

b. G. Cognitive Focus: When one analyzes the situation, uses previous experiences and applies strategies in order to resolve the problem effectively.

c. M. Emotional Focus: When one becomes quick tempered or aggressive toward others or when withdraws, feels guilty.

2. Social Support implies that the person seeks for help in cognitive (advice, information) or emotional terms (the need of a person to be heard by somebody and be accepted). It also implies the use of collaboration as a mean of facing stress. This strategy includes 3dimensions:

a. M. Collaboration means that one has the need to work with others. b. H. Informative Social Support describes that one addresses to others in order to gain information regarding the situation that creates the problem.

c. N. Emotional Social Support informs one's feelings of the need to speak to somebody, in order to receive comfort or sympathy.

3. Withdrawal indicates that the subjects isolate themselves, try not to think of the problem, are led to day-dreaming or imagination or adopt addictive behaviour (e.g. food, drugs, smoking, medication and so on). This strategy is divided into 3dimensions:

a. C. In the Behavioural and Social Withdrawal individuals withdraw into themselves and isolate from others.

b. I. The persons with Mental Withdrawal try to avoid or deny thinking the problem, strive to forget through daydreaming, sleep or are self-distracted.

c. O. with Addiction one seeks substitutes through food, medication, drugs, tobacco and so on.

4. Change of Attitude Implies modification of behaviour, of cognitive aspects (acceptance) or values (when the individual 
turns to God, acquires a philosophy of life or jokes with regard to the problem). This strategy has 3 dimensions:

a. D. Behavioural Change which modifies person's actions, behaviour, and the way of life with regard to the problem.

b. J. With acceptance one acknowledges the problem or learns to live with it.

c. P. Change of Values occurs when somebody turns to God (attitude of faith), turns to another philosophy of life, or relativises the situation in an amusing manner (humour).

5. Control entails domination over the situation, the coordination of behaviours or activities and the withholding of emotions. This strategy has 3dimensions:

a. E. For the regulation of activities one resists the impulse to make impetuous decisions or takes constrained decisions.

b. K. With cognitive control and planning one sets aims and elaborates on them.

c. Q. Persons with emotional control do not panic or express the emotions they feel to others.

6. Denial involves acts as if the problem does not exist; try to have fun and do something more pleasant. The subject experiences difficulties in describing emotions. This strategy has also 3dimensions:

a. F. Amusement helps the person to think something different rather than the problem deals with other activities in order to stop thinking of the stressful situation and seeks satisfaction in other facets of life.

b. L. Someone with denial attempts to reject the reality of a stressful situation.

c. R. With alexithymia one has difficulty to describe his/ her feelings to other people, few dreams or fantasies due to restricted imagination.

Combining the sections and strategies, the subject is found to adopt positive or negative coping strategies according to the way in which one helps himself to function adequately or not in a stressful event. Specifically, 9 coping strategies (A, G, B, H, N, J, K, Q and F) are characterized as positive, while the remaining $9(\mathrm{M}, \mathrm{C}, \mathrm{I}, \mathrm{O}, \mathrm{D}, \mathrm{P}$, $\mathrm{E}, \mathrm{L}$ and $\mathrm{R}$ ) are characterized as negative.

Table I The three sections and the general amount of coping strategies chosen by the majority of participants

\begin{tabular}{lll}
\hline & Mean /Max & Percentage of Students \\
\hline Action & $54,17 / 90$ & $95,5 \%$ \\
\hline Information seeking & $55,19 / 90$ & $95.90 \%$ \\
\hline Emotion & $50,19 / 90$ & $95,2 \%$ \\
\hline Positive strategies & $89,62 / 135$ & $95,9 \%$ \\
\hline Negative strategies & $69,88 / 135$ & $94,8 \%$ \\
\hline $\begin{array}{l}\text { General index of } \\
\text { coping strategies }\end{array}$ & $159,52 / 270$ & $95,5 \%$ \\
\hline
\end{tabular}

\section{Statistical analysis}

Every coping strategy of each section (in total $18=6$ Strategies x 3 Fields) was studied based on 3 statements. All statements were analyzed by means of a 5 -point rating scale $(1=$ never, $2=$ seldom, $3=$ sometimes, $4=$ often, $5=$ always) with consideration of the way of coping strategies in a stressful event. The maximum rating (value) was 15 for each coping strategy of each field. T-tests and ANOVA
(Analysis of Variance) were performed in order to demonstrate whether the mean indexes for the various groups of participants were statistically significant differences. The post-hoc Tukey control was further performed for each comparison. All analyses were completed using the SPSS (Statistical Package for Social Sciences), with the method of Kolmogorov-Smirnov. The level of significance is $\alpha=.05$ ? For all the tests performed.

Table 2 The percentage of participants responded to the six coping strategy

\begin{tabular}{lll}
\hline Coping Strategies & Mean & Percentage \\
\hline Focus & $28,78 / 45$ & $94,7 \%$ \\
\hline Social Support & $28,63 / 45$ & $94,7 \%$ \\
\hline Withdrawal & $21,38 / 45$ & $95,2 \%$ \\
\hline Change & $27,6 / 45$ & $95,1 \%$ \\
\hline Control & $28,93 / 45$ & $96,1 \%$ \\
\hline Denial & $24,76 / 45$ & $94,8 \%$ \\
\hline
\end{tabular}

\section{Results}

The scale's reliability was established through estimation of the internal consistency of the scale used in the present study. The results were: Cronbach's alpha a $=0,9206$, Reliability Coefficients 12 items, Alpha $=0,9047$ and Standardized item alpha $=0,9206(\mathrm{n}=990)$. The results revealed high internal consistency between the questions and, therefore, high reliability of the scale used. Table 1 provides mean values for each three fields and for total positive, total negative and general index of coping applied by the participants. Among fields the majority of the participants use Information Seeking (95.9\%) to control the academic stress. Most of the participants apply positive coping strategies $(95.9 \%)$ in higher extend. Table 2 provides the composed scale used in the current study and the percentage of respondents chose for each coping strategy. Among strategies the high mean value corresponds to Control as a coping strategy. It seems that the majority of the subjects $(96.1 \%)$ use Control to alleviate stress in higher extend. The lowest mean value is obtained for Withdrawal (mean 95, 2\%, $\mathrm{m}=21,38)$ and Denial $(94.8 \%, \mathrm{~m}=24,76)$.

\section{Statistical correlations}

\section{Correlation between gender of participants and coping strategies}

The statistical analysis revealed statistically significant differences for most of the coping strategies. Specifically, the mean value in women was higher than the mean value in men in Action $(p<0,001)$, Information $(p<0,001)$, Emotion $(p<0.001)$, Positive Strategies $(p<0,001)$, Negative Stategies $(p<0,001)$, Focus $(p<0,001)$, Social Support $(p<0,001)$, Withdrawal $(p<0,001)$ and Change $(p<0,001)$. According to the findings, women tend to apply more coping strategies than men, in general (Table 3). The results of the current study indicated that there was no significant difference between men and women in the Control strategy $(\mathrm{t}=1,33, \mathrm{df}=988, \mathrm{NS})$ and Denial $(\mathrm{t}=-0,79, \mathrm{df}=988, \mathrm{NS})$

\section{Correlation between indexes and age of participants}

The correlation between the coping strategies and participants' age range, confirmed that there was no statistically significant difference, in any of the studied strategy.

\section{Correlation of the indexes and the place of origin of participants}

When the cohort was divided in those participants who were raised in southern Greece and those in northern Greece, it was found no 
significant difference, between the two groups in all coping strategies, besides the Emotion $(\mathrm{F}=3.030, \mathrm{df}=988, \mathrm{P}<0.01)$ and Focus strategies strategy $(\mathrm{F}=3.415, \mathrm{df}=988, \mathrm{p}<0.001)$, as shown in Table 4. Thus, it is revealed that there are no cultural deferences regarding coping between students coming from North or South part of the country. It was revealed, therefore, by the present research that there were only some significant differences of coping strategies on emotion $(\mathrm{F}=3.030$, $\mathrm{DF}=988, \mathrm{P}<0 . \mathrm{o1})$ and Focus strategies $(\mathrm{F}=3.415, \mathrm{df}=988, \mathrm{P}<0.01)$ but there were not on the rest of the strategies (Table 5).

\section{Correlation between strategies and institute's geographical location}

The correlations between strategies and institute's geographical location revealed statistically significant difference for the emotion index $(\mathrm{F}=-3.489, \mathrm{df}=3.986, \mathrm{p}<0.05)$. Specifically, students studying in Athens use more coping strategies focused on emotion than participants studying in Kozani ( $m=51,32$ vs. 49,19$)$. It should be noted that, although, statistical analysis did not reveal any further significant differences, the mean value of students in Athens that use emotional strategies $(m=: 51,32)$ was, also, higher than the mean value of students in Patras $(m=50,18)$ and in Volos-Larisssa $(m=49,90)$. As for positive strategies index, post-hoc Tukey control analysis revealed statistically significant difference between participants studying in Volos-Larissa and Athens $(\mathrm{p}<0.0001)$, those who study in Patras and Athens $(p<0.01)$, and those who study in Kozani and Athens $(p<0.01)$; it is clear that students enrolled in peripheral Institutions (Volos, Larissa, Patras and Kozani) compared with participants studying in Institutions located in the capital (Athens) use more positive strategies than students in Athens. The total coping strategies index $(\mathrm{F}=3.489$, $\mathrm{df}=3.159, \mathrm{p}<0.05)$. Tukey control revealed statistically significant difference for the total coping strategies index between participants studying in Kozani and Athens $(\mathrm{p}<0.05)$. The percentage of students in Athens choosing a great variety of coping strategies $(94,7 \%)$ was higher than that of students in Kozani $(92,2 \%)$. Regarding the focus index $(\mathrm{F}=5.636, \mathrm{df}=3.986, \mathrm{p}<0.0001)$, Tukey control showed significant difference between participants who study in Volos, Larissa and Athens $(p<0.05)$ but also between those who study in Kozani and Athens $(\mathrm{p}<0.01)$. Concerning the social support index $(\mathrm{F}=4.327$, $\mathrm{df}=3.986, \mathrm{p}<0.01$ ), it was found a significant difference by the Tukey control between participants who study in Volos-Larissa and Athens $(p<0.05)$, those who study in Patras and Athens $(p<0.05)$, as well as those who study in Kozani and Athens ( $p<0.01)$. More specifically, the percentage of participants that use the strategy of social support and study in Volos-Larissa $(97,2 \%)$ and in Patras $(96,4 \%)$ was higher than the percentage of those studying in Athens (95,1\%). In contrast, the percentage of subjects that use the strategy of social support and study in Kozani $(89,7 \%)$ was lower than the percentage of those studying in Athens $(95,1 \%)$. The denial index findings were $(\mathrm{F}=3.199, \mathrm{df}=3.986$, $\mathrm{p}<0.05)$. This significant difference by the Tukey control was found between the participants who study in Volos, Larissa and Patras $(p<0.05)$. There was no statistical significant difference for allover coping strategies or indexes. In summary, referring to the institute's geographical location, the difference was found to be statistically significant for the indexes. The results of the correlation between all strategies and the participants' place of study are summarized in Table 6. It is worth noting that the place of study influences interestingly the coping strategies chosen by the and we think that this is an important research finding. Correlation of the indexes and type of institution.

The results of the correlation between the types of strategies used and the type of Institution the participants were enrolled, showed that students studying in Professional Learning Institutes compared to those from Technological Institutes or Universities apply more coping strategies in general $(p<0,05)$. The statistical analysis revealed statistical significant differences in positive strategies index $(p<0.01)$, action ( $p<0,0001)$, focus $(p<0,001)$ and control ( $<<0,0001)$, coping strategies between the Professional Learning Institutes and the Technological Institutes/Universities. As for the strategy Change, post-hoc Tukey control revealed statistically significant difference on the coping style of the participants; depending on the type of Institution they were enrolled. This difference was evident between students of Professional Learning Institutes and Universities $(\mathrm{F}=3,088$, df $=2,987$, $p<0,05)$. More precisely, the percentage of participants who use the change index and study at Professional Learning Institutes $(92,0 \%)$ is lower than the percentage of those who study at Universities $(97,6 \%)$. It seems that students that study in Universities are willing to change in order to cope with stress and difficult life situations.

Table 3 Correlation between three coping strategy sections and participants' gender

\begin{tabular}{|c|c|c|c|c|c|c|c|}
\hline Coping strategy & $\begin{array}{l}\text { Mean } \\
\text { Value } \\
\text { (men) }\end{array}$ & $\begin{array}{l}\text { Standard } \\
\text { Deviation } \\
\text { (men) }\end{array}$ & $\begin{array}{l}\text { Mean } \\
\text { Value } \\
\text { (women) }\end{array}$ & $\begin{array}{l}\text { Standard } \\
\text { Deviation } \\
\text { (women) }\end{array}$ & t-value & Df & p-level \\
\hline Action & 53,26 & 7,27 & 54,76 & 6,96 & $-3,25$ & 988 & $p<0,0001$ \\
\hline Information & 53,94 & 7,95 & 56,00 & 7,50 & $-4,13$ & 988 & $\mathrm{p}<0,000$ \\
\hline Emotion & 48,51 & 7,74 & 51,23 & 7,06 & $-5,70$ & 988 & $\mathrm{p}<0,000$ I \\
\hline Positive strategies & 87,23 & 11,69 & 91,18 & $\mathrm{II}, 24$ & $-5,32$ & 988 & $\mathrm{p}<0,000$ I \\
\hline Negative strategies & 68,41 & 12,70 & 70,84 & $\mathrm{II}, 54$ & $-3,12$ & 988 & $\mathrm{p}<0,0$ l \\
\hline Total of coping strategies & 155,74 & 19,17 & $|62,0|$ & 17,84 & $-5,24$ & 988 & $P<0,000$ I \\
\hline Focus & 28,28 & 4,82 & 29,10 & 4,86 & $-2,60$ & 988 & $\mathrm{p}<0,0$ l \\
\hline Social Support & 26,91 & 5,84 & 29,77 & 5,46 & $-7,83$ & 988 & $\mathrm{p}<0,000 \mathrm{I}$ \\
\hline Withdrawal & 20,61 & $5,4 I$ & 21,89 & 4,80 & $-3,89$ & 988 & $\mathrm{p}<0,000$ I \\
\hline Change & 26,13 & 5,15 & 27,66 & 4,66 & $-4,85$ & 988 & $\mathrm{p}<0,000$ I \\
\hline Control & 29,18 & 4,69 & 28,77 & 4,63 & I,33 & 988 & NS \\
\hline Denial & 24,60 & 5,36 & 24,87 & 4,90 & $-0,79$ & 988 & NS \\
\hline
\end{tabular}

\section{Discussion and Conclusion}

The results of this exploratory study generated a wealth of information about the type of coping strategies used by Greek students, in order to operate stress, due to the enrollment in a demanding academic environment, such as Higher Education. The questionnaires were distributed to a total of 999 participants. The research questions focused on the correlation between the coping strategies: action, information, emotion, positive strategies, negative strategies, total coping strategies, control, change, focus 
denial, withdrawal and social support and demographic parameters: gender, age, place of origin, place of study and institution of study. The results showed that there was statistically significant difference between men and women which appeared in most types of coping strategies. Women were found to apply more coping strategies than men, in general. Interestingly, age did not appear to be a factor. Probably, this was due to the fact that all participants belonged to the same age group. Additionally, concerning the place of origin of the participants, statistically significant differences for most indexes were not detected;. Instead, differences were found, only, for the Emotion and the Focus indexes. Further on, as far as the correlation between the indexes and the geographical location of the institute, for most of the indexes, there were statistically significant differences between the averages depending on the place of study of the participants. It was clear that students enrolled in peripheral Institutions (Volos, Larissa, Patras and Kozani) compared to participants studying in Institutions located in the capital (Athens) use more positive strategies than students in Athens. This finding might be due to enviroment's influence in psychological well-being. As a matter of fact physical surroundings and social environment is quite different in small student cities. Moreover, urban environment of big cities alters people psychology differently in comparison with rural environment. Additionally, colleges and universities in small cities and eventually rural areas often mean a smaller number of students within an institute, which eventually leads to receiving a personalised attention, allowing for a more interactive educational experience which could decrease academic stress. Furthermore, the feeling of community at an urban college may not be as strong, due to impersonal nature of interaction between the students and teaching stuff. Coping responses can also shift in relation to change in the individual's interaction with the environment. Quite often, the trajectory of coping can be powerfully shaped by changes in circumstances. After all, coping is in part determined by the use and perception of available resources in the individual's social, institutional and physical surroundings, according to Gottlieb (1997). Furthermore, as it is well known, physical surroundings affect positively people's well-being. ${ }^{25}$ Changes in social networks and institutional resources to which people have access affect their attitudes and value systems. College environment alters students' lives and their dealing with stress. Besides, learning environment affects students' coping styles regarding to emotional and behavioural problems. ${ }^{26}$ Kerdijk's study was the first to provide novel findings of the effect that the social environment can have on the stress and coping of team athletes and suggests that others can influence the coping with stress. ${ }^{27}$ As Gottlieb states, "Changes in the external environment can affect coping both directly and indirectly" (1997). They can have a direct effect by improving or blocking individuals' access to valued social and material resources; whereas they can exercise an indirect effect on several forms of psychological coping. A review of the literature revealed limited information regarding study's place influence to students' coping. As far as we know, this is the first study presenting findings correlating place of study's influence on coping strategies. This is an important strength in the field of the research of students' coping strategies. Finally, the correlation between the indexes and the type of institutions participants were enrolled (University-Technological Educational Institute-Professional Learning Institute) revealed statistically significant differences for the Action Index, Positive Strategies Index, Total of coping strategies, and for Change, Control and Focus coping strategies. These statistical differences were found between Professional Learning Institutes and Technological Educational Institutes, and, also, between Professional Learning Institutes and Universities..$^{28,29}$

Table 4 Correlation between strategies and place of origin of participants

\begin{tabular}{|c|c|c|c|c|c|c|c|}
\hline & $\begin{array}{l}\text { Mean } \\
\text { Value } \\
\text { (South } \\
\text { Greece) }\end{array}$ & $\begin{array}{l}\text { Standard } \\
\text { Deviation } \\
\text { (South } \\
\text { Greece) }\end{array}$ & $\begin{array}{l}\text { Mean } \\
\text { Value } \\
\text { North } \\
\text { Greece }\end{array}$ & $\begin{array}{l}\text { Standard } \\
\text { Deviation } \\
\text { (North } \\
\text { Greece) }\end{array}$ & $\begin{array}{l}\mathrm{t}- \\
\text { values }\end{array}$ & Df & p-level \\
\hline Action & 54,29 & 7,12 & 54,01 & 7,13 & 0,621 & 88 & NS \\
\hline Information & 55,28 & 7,70 & 55,07 & 7,80 & 0,434 & 88 & NS \\
\hline Emotion & 50,79 & 7,49 & 49,35 & 7,34 & 3,030 & 88 & $P<0,0$ I \\
\hline Positive strategies & 90,13 & $1 \mathrm{I}, 45$ & 88,97 & $1 \mathrm{I}, 72$ & 1,570 & 88 & NS \\
\hline Negative strategies & 70,26 & 12,19 & 69,39 & 11,89 & 1,129 & 988 & NS \\
\hline Total index of coping start Coping strategies & 160,37 & 18,57 & 158,44 & 18,66 & 1,619 & 988 & NS \\
\hline Focus & 29,24 & 4,98 & 28,19 & 4,63 & 3,415 & 988 & $p<0,00$ I \\
\hline Social Support & 28,84 & 5,63 & 28,37 & 5,96 & $\mathrm{I}, 270$ & 988 & NS \\
\hline Withdrawal & 21,64 & 4,97 & 21,05 & 5,22 & $1,8 \mid 4$ & 988 & NS \\
\hline Change & 26,98 & 4,86 & 27,16 & 4,98 & $-0,577$ & 988 & NS \\
\hline Control & 29,00 & 4,66 & 28,84 & 4,66 & 0,564 & 988 & NS \\
\hline
\end{tabular}

Table 5 Correlation between strategies and place of study of participants

\begin{tabular}{llll}
\hline Indexes & Df & F & p-level \\
\hline Action & 3,986 & $\mathrm{I}, 804$ & $\mathrm{NS}$ \\
Information & 3,986 & 2,268 & $\mathrm{NS}$ \\
Emotion & 3,986 & 3,489 & $\mathrm{P}<0,05$ \\
Positive strategies & 3,986 & 7,213 & $\mathrm{P}<0,000 \mathrm{I}$ \\
Negative strategies & 3,986 & 2,984 & $\mathrm{P}<0,05$ \\
Total index of coping strategies & 3,986 & 3,159 & $\mathrm{P}<0,05$ \\
Focus & 3,986 & 5,636 & $\mathrm{P}<0,00 \mathrm{I}$ \\
Social Support & 3,986 & 4,327 & $\mathrm{P}<0,0 \mathrm{I}$ \\
Withdrawal & 3,986 & 2,025 & $\mathrm{NS}$ \\
Change & 3,986 & $\mathrm{I}, 550$ & $\mathrm{NS}$ \\
Control & 3,986 & 0,607 & $\mathrm{NS}$ \\
Denial & 3,986 & 3,199 & $\mathrm{P}<0,05$ \\
\hline
\end{tabular}


Table 6 Correlation between indexes and type of institution

\begin{tabular}{llll}
\hline Coping strategies & Df & F & p-level \\
\hline Action & 2,987 & $\mathrm{II}, 2 \mathrm{I0}$ & $\mathrm{P}<0,000 \mathrm{I}$ \\
Information & 2,987 & 0,856 & $\mathrm{NS}$ \\
Emotion & 2,987 & $\mathrm{I}, 007$ & $\mathrm{NS}$ \\
Positive strategies & 2,987 & $6,5 \mathrm{I} 4$ & $\mathrm{P}<0,0 \mathrm{I}$ \\
Negative strategies & 2,987 & 0,457 & $\mathrm{NS}$ \\
Total index of coping strategies & 2,987 & 3,904 & $\mathrm{P}<0,05$ \\
Focus & 2,987 & $5,53 \mathrm{I}$ & $\mathrm{P}<0,00 \mathrm{I}$ \\
Social Support & 2,987 & $\mathrm{I}, 090$ & $\mathrm{NS}$ \\
Withdrawal & 2,987 & 0,084 & $\mathrm{NS}$ \\
Change & 2,987 & 3,088 & $\mathrm{P}<0,05$ \\
Control & 2,987 & 8,476 & $\mathrm{P}<0,000 \mathrm{I}$ \\
Denial & 2,987 & 0,244 & $\mathrm{NS}$ \\
\hline
\end{tabular}

\section{Limitations of the Study}

This study's sample consisted of 999 students coming from the Greek university cities. The results might be different, if the participants were more, from different age groups and more faculties. This population's characteristics might also be different in comparison to students studying abroad and/or other countries. So, a transcultural study would be very interesting. In conclusion, coping plays a crucial role in the stress management, because the proper use of effective strategies leads to an adjustment of the situation and a normalization of emotions. This research is of great value because by determining the percentage of students and the type of strategies they use to cope with daily, stressful situations. Finally, we could indicate and support the need for youth counselling in Higher Education Institutes. It would be interesting to study in the future how different majors i.e. medicine, technical or art may influence the type of strategies used and possible identify students subgroups, who use negative strategies and counsel them or guide them on how to manage their stress in an effective way.

\section{Acknowledgments}

None.

\section{Conflicts of interest}

Author declares there are no conflicts of interest.

\section{Funding}

None.

\section{References}

1. Niemi PM, Vainiomaki PT. Medical students' academic distress, coping, and achievement strategies during the preclinical years. Teaching and Learning in Medicine. 1999; 11(3):125-134.

2. Shaikh BT, Kahloon A, Kazmi M, et al. Stress management in medical students. J Coll Physicians Surg Pak . 2004;14(5):306.

3. Gall TL, Evans, DR, Bellerose S. Transition to first-year university: Patterns of change in adjustment across life domains and time. Journal of Social and Clinical Psychology. 2000; 19(4):544-567.

4. Shields N. Stress, Active Coping, and Academic Performance Among Persisting and Nonpersisting College Students. Journal of Applied Biobehavioral Research. 2001;6(2):65-81.

5. Efstathiou G, Efthimiou K, Kalantzi-Azizi A. Psychological needs, attitudes and students' expectations in relation to the function of Consultation Centres of Students, Minutes of the Psychology Convention in Cyprus under the title of: "Psychology today: Cypriotic and European Reality. Psychology Association, Cyprus. 2003.
6. Dwyer AL, Cummings AL. Stress, Self-Efficacy, Social Support, and Coping Strategies in University Students. Canadian Journal of Counselling and Psychotherapy / Revue canadienne de counseling. 2001;35(3):208-220.

7. Lazarus RS. Coping theory and research: past, present, and future. Psychosom Med. 1993;55(3):234-247.

8. Folkman S. Personal control and stress and coping processes: a theoretical analysis. J Pers Soc Psychol. 1984;46(4):839-852.

9. Bird GW, Melville K. Families and intimate relationships; Stress:Individual and family perspectives . McGraw Hill, USA. 1994.

10. Guthrie EA, Black D, Shaw CM, et al. Embarking upon a medical career: psychological morbidity in first year medical students. Medical Education. 1995;29(5):3377-41.

11. Miller PM, Surtees PG. Psychological symptoms and their course in first-year medical students as assessed by the Interval General Health Questionnaire (I-GHQ). Br J Psychiatry . 1991;159:199-207.

12. Dritsas I, Theodoratou M. Findings from a Large-Scale Empirical Research on Substance Abuse Prevention in Greece. Glob J Add \& Rehab Med. 2017;2(5):555598.

13. Dunkley DM, Blankstein KR, Halsall J, et al. The relation between perfectionism and distress: Hassles, coping, and perceived social support as mediators and moderators. Journal of Counseling Psychology. 2000;47: 437-453.

14. Pritchard ME, Wilson GS, Yamnitz B. What predicts adjustment among college students? A longitudinal panel study. J Am Coll Health. 2007;56(1):15-21.

15. Sigmon ST, Stanton AL, Snyder CR. Gender differences in coping: A further test of socialization and role constraint theories. Sex Roles. 1995;33:565-587.

16. Felsten, G, Wilcox K. Influences of Stress and Situation-Specific Mastery Beliefs and Satisfaction with Social Support on Well-Being and Academic-Performance. Psychological Reports. 1992;70(1):291-303.

17. Li H, Lin C. College Stress and Psychological Well-Being of Chinese College Students. Acta Psychologia. 2003;35(2):222-230.

18. Mundt MH. Peer interviewing: a student health survey on an urban campus. J Am Coll Health. 1996;44(5):187-192.

19. Bonica C, Daniel JH. Helping adolescents cope with stress during stressful times. Curr.Opin.Pediatr. 2003;15(4):385-390.

20. Esparbes S, Sordes Ader F, Tap P. Presentation de l'echelle de coping. In: Universite de Toulouse-Le-Mirail (Ed.), Actes de las Journees du Laboratoire Personnalisation et Changements Sociaux. France. 1993. p.89-107. 
21. Esparbes-Pistre S, Sordes-Ader F, Tap P. Strategies de personnalisation etappropriation de competences a l'adolescence: differences entre garcons et filles. In: Lescarret O \& M Leonaridis De (Eds.), Séparation des sexes et compétences, L' Harmattan, France. 1996. p.247-277.

22. Theodoratou M. Scale Evaluating Coping Strategies. In: Stalikas A (Ed.), The psychometric tools in Greece. Ellinika Grammata, Greece. 1999.

23. Theodoratou M, Andreopoulou O, Bekos V, et al. Culture specific stress coping strategies used to alleviate occupational stress among Greek nursing personnel. Journal of Medical Psychology. 2009;1:23-31.

24. Theodoratou M. Maturation and Group Dynamics:Contribution in group counseling. Rossili, Greece. 2006.
25. Ulrich R. Collected research on the relationship between types of visual landscapes \& psychological well-being. USA. 1987.

26. Thuen E. Learning environment, students' coping styles and emotional and behavioural problems. Norway. 2014. p.1-105.

27. Kerdijk C, Van der Kamp J, Polman R. The Influence of the Social Environment Context in Stress and Coping in Sport. Front Psychol. 2016;7:875.

28. The College environment. 1968;3(3):318-322

29. Sasaki M, Yamasaki K. Stress coping and the adjustment process among university freshmen. Counselling Psychology Quarterly. 2007;20(1):51-67. 